\title{
Role of Mc1r in UV-Induced Melanoma in Animal Models
}

\section{Agnieszka Wolnicka-Glubisz*}

Department of Biophysics, Faculty of Biochemistry, Biophysics and Biotechnology, Jagiellonian University, Krakow, Poland

*Corresponding author: Agnieszka Wolnicka-Glubisz, Department of Biophysics, Faculty of Biochemistry, Biophysics and Biotechnology, Jagiellonian University, ul. Gronostajowa 7, 30-387 Kraków, Poland, Tel: 48-12-6646526; Fax: 48-12-6646901; E-mail: a.wolnicka-glubisz@uj.edu.pl

Received date: Oct 22, 2014, Accepted date: Nov 27, 2014, Published date: Nov 30, 2014

Copyright: () 2014 Wolnicka-Glubisz A, et al. This is an open-access article distributed under the terms of the Creative Commons Attribution License, which permits unrestricted use, distribution, and reproduction in any medium, provided the original author and source are credited.

\begin{abstract}
The role of UV and pigmentation are very difficult to control for in human studies, and mechanisms difficult to infer based on statistical association with melanoma. The animal models are not representative of the human situation. But on the other hand, animal studies can be useful for basic studies that will ultimately help in building up a picture of the overall network of in vivo cellular behavior and intra and inter cellular pathways contributing to melanoma progression and the effects (or not) of UV radiation in individuals with MC1R variants.
\end{abstract}

This review describes that, although the $\mathrm{Mc} 1 \mathrm{r}$ is a determinant of coat color phenotype as the MC1R is a determinant of hair and skin color in humans, deficiency of the Mc1r in mice is associated with a paradoxical lower incidence of melanoma.

Keywords: Mc1r; melanoma; UV; HGF; c-Met; B-Raf; mouse model

\section{MC1R and Mclr}

The melanocortin-1 receptor (MC1R) is a member of the Gprotein-coupled receptor (GPCR) superfamily the ligand for which, alpha-melanocyte stimulating hormone ( $\alpha-\mathrm{MSH})$, is derived from the proopiomelanocortin (POMC) precursor protein [1,2]. MC1R present in melanocyte membrane is involved in melanogenesis where it regulates the amount and type of melanin production and thus human skin phototype and its sensitivity to UV induced damage [3,4]. There are two main types of melanin: pheomelanin (red/yellow) and eumelanin (brown/black), which are derived from the same precursor dopaquinone that is formed following oxidation of tyrosine by tyrosinase $[5,6]$. However while synthesis of eumelanin requires MC1R activity, the synthesis of pheomelanins is a default pathway which proceeds in the absence of MC1R signaling [7]. In pigmented tissues such as skin melanin is present as mixtures or copolymers of both types [8]. MC1R engagement with its ligands, $\alpha$-MSH or adenocorticotropic hormone (ACTH) activates adenyl cyclase (AC), resulting in cAMP production, which leads to phosphorylation of cAMP responsive-element-binding protein (CREB), a member of the transcription factor family [6]. CREB activates microphthalmia transcription factor (MITF) which activates the enzyme tyrosinase [6]. The MC1R coding region in humans is highly polymorphic with at least 30 allelic variants, most of which result from a single amino-acid substitution [8]. Also in other mammals similar single polymorphisms as well as mutations causing frame shifts and truncated Mclr variants have been found [9].

In mouse hair, signaling through the Mclr acts as a control point for determining the eumelanin/phaeomelanin ratio and its loss of function or mutations results in yellow coat color [10]. The hair of the Mc1r mouse is often used in EPR analysis as a natural standard of pheomelanin although it should be noted that it does not contained pure pheomelanin $[11,12]$. In the recessive yellow mouse $\left(\mathrm{Mc} 1 \mathrm{r}^{\mathrm{r} / \mathrm{e}}\right.$, extension mutation), a frame shift mutation in the Mclr gene causes deletion of a single nucleotide at position 549 of the open reading frame and results in a premature stop after 12 additional codons, the result of which is premature termination in the fourth transmembrane domain of the receptor protein making it unable to couple to AC and activate cAMP $[13,14]$. The Mclr receptor in the mouse thus differs from the human polymorphisms in MC1R which encode a complete receptor, albeit one with altered function, although there is $76 \%$ identity in amino acid sequence. In the mouse Mc1r the receptor is truncated and the ability to engage cAMP is totally absent.

There are differences between MC1R and Mc1r. Mc1r required a higher concentration of $\alpha-\mathrm{MSH}$ [13] and is less sensitive to exogenous ligands like agouti signaling protein (ASP) which acts as an extracellular antagonist of Mclr signaling [14,15]. The difference in potency is compensated in vivo by expression of a higher number of Mc1r receptors on mouse than on human melanocytes [16,17]. Moreover, it seems that signaling by $\mathrm{Mclr}$ is largely ligandindependent in vivo, as loss of POMC, the precursor of $\mathrm{a}-\mathrm{MSH}$, in C57BL/6 mice preserved eumelanin hair pigmentation [18], while most individuas that lack POMC have red hair $[19,20]$.

\section{UV-Induced Melanoma}

Damage to epidermal melanocytes plays a critical role in the development of malignant melanoma (CMM), which occurs in skin, but is also found in other parts of the body, including the bowel and the eye (uveal melanoma). It is one of the most lethal types of cancers. A causal role for solar UV exposure, in etiology of cutaneous melanoma is widely accepted. UV radiation, that reaches the earth surface consists mainly of UVA $(95 \% ; 320-400 \mathrm{~nm})$, and about $5 \%$ of UVB $(280-320 \mathrm{~nm})$. UVC $(200-280 \mathrm{~nm})$ is completely absorbed by the earth's atmosphere. Stratospheric ozone depletion, leads to increases doses of UVB transmitted to the Earth, which increases the risk for skin cancer including melanoma [22]. Epidemiologic studies indicate increased susceptibility of children to UV-induced melanoma [23,24]. Studies on a mouse model for UV-induced melanoma, confirmed that exposure to UV of neonatal but not adult HGF/SF(Hepatocyte growth 
factor/scatter factor) transgenic mice resulted in development of melanoma within a year of treatment [25-28]. HGF/SF transgenic mouse in which mouse HGF/SF cDNA sequences were overexpressed by virtue of a mouse metallothionein (MT) gene promoter and associated locus control regions [29,30], has an increased number of extra-follicular dermal melanocytes in the trunk skin, that imitate human skin (melanocytes are present in the skin, in contrast to wild type mouse which has melanocytes present only in hair follicles). In contrast to other animal model, in which only dermal-animal melanoma occurs, neonatal HGF transgenic mice are susceptible to UV-induced melanoma which, uniquely among melanoma mouse models, recapitulate the histopathology of human disease, namely superficial spreading melanoma (SSM) [25-28]. The mechanism of juvenile susceptibility to melanoma is not well known. However our studies on HGF/SF transgenic mice suggest that the immaturity of melanocytes in the skin and the profound defect in the immune response, of UV-induced DNA damage, play an important role in the susceptibility of juvenile mice to UV-induced malignant melanoma $[24,28]$.

\section{Mc1r and Immune System}

In addition to cutaneous and hair follicle melanocytes, keratinocytes and fibroblasts, MC1R expression was also found on macrophages, lymphocytes, neutrophils and dendritic cells [3], suggesting a role not only in skin physiology and melanogenesis but also in inflammation. Melanotropins have been reported to possess anti-inflammatory effects in many experimental models of acute and chronic inflammation, including bowel diseases, allergy and others $[31,32]$. MC1R is subject to regulation by a variety of paracrine and/or autocrine factors that are synthesized in response to UV exposure of the skin such as $\alpha-\mathrm{MSH}$ and ACTH, both derived from POMC, and which protect from UV induced DNA damage and apoptosis [3,32-34]. Most of the studies to date have focused on the antiinflammatory properties of $\alpha$-MSH from which it has been concluded that lack of MC1R may increase UV sensitivity [35]. There is ample published evidence that UV upregulates $\alpha-\mathrm{MSH}$ in keratinocytes and in melanocytes [36]. UVB has also been elegantly demonstrated to upregulate expression and protein levels of POMC in cultured human skin explants [37]. There is evidence that UV upregulates $\alpha$-MSH in human skin in vivo. Holzmann et al. [38] reported increased levels of circulating both $\alpha$-MSH and ACTH in humans in response to UVA irradiation in fair-skinned individuals [38]. In mouse skin Cui et al. [40] found that UVB irradiation of mice increased epidermal POMC protein levels in a p53 dependent manner, consistent with their in vitro studies. The total UVB dose used was $2 \mathrm{~kJ} / \mathrm{m}^{2}\left(40 \mathrm{~J} / \mathrm{m}^{2} /\right.$ day 5 days a week for 10 weeks). In the same study these investigators showed increased $\alpha$-MSH in cultured human foreskins irradiated with UVC (254 nm germicidal lamp) [39] although it should be noted that $254 \mathrm{~nm}$ UVC is not a component of sunlight and thus has limited biologic relevance. The MC1R has been suggested as the receptor responsible for the anti-inflammatory effects of $\alpha-\mathrm{MSH}$ and related peptides via inhibition of NF- $\kappa B$ activation $[40,41]$ and protection of I $\mathrm{BB} \alpha$ degradation [42]. This results in reduction of the expression of pro-inflammatory cytokines [42] and adhesion molecules [41], therefore affecting the humoral and cellular phases of inflammation $[43,44]$. Further, Grabbe et al. [45] found that $\alpha-\mathrm{MSH}$ decreased contact hypersensitivity and induced immune tolerance in mice, indicating an immunosuppressive role [45].
However, there are inconsistent studies using $\mathrm{Mcl} \mathrm{r}^{\mathrm{e} / \mathrm{e}}$ yellow mice with a deficiency in Mc1r to investigate the effects of the Mc1r on inflammation and immunity. Using an model of inflammatory peritonitis, Getting et al. [46] found that Mc3r not Mc1r was responsible for the anti-inflammatory effect [46]. In contrast, Maaser et al. [47] found a crucial role for Mclr in experimental colitis [47]. We have recently demonstrated, however, that lack of Mclr in mice did not alter an inflammatory response to UV in their skin. For all tested groups of mice: C57BL/6-c (albino),C57BL/6-Mc1r ${ }^{\mathrm{e} / \mathrm{e}}$ (yellow), and $\mathrm{C} 57 \mathrm{BL} / 6$ (black) formation of DNA damage as CPD, edema, determined as increase in skin thickness, and infiltrating neutrophils as a percentage of total skin cells after UV irradiation at selected time points remained similar, suggesting that Mclr does not influence the inflammatory response in mice. We also found that lack of Mclr did not alter either neonatal immune tolerance or UV immunosuppresion [48]. Our findings were confirmed by other researchers [see commentaries in Experimental Dermatology [49,50].

\section{MC1R and Susceptibility to Melanoma}

In human melanoma MC1R polymorphisms are well described as significantly increasing melanoma risk. However only some of these polymorphisms, such as R151C, R160W and D249H that encode hypomorphic mutants that are unable to either bind ligand or activate $\mathrm{AC}$ are associated with red hair in a Caucasian population $[9,51]$ and these show the highest risk for melanoma. The "red-head" phenotype (phototype I) is defined not only by hair color but also by light skin, poor tanning ability and sensitivity for sunburn [52] and increased skin cancer including melanoma susceptibility [35,53-55]. Studies on human melanocytes derived from individuals with one of these three mutations showed that loss of function in the MC1R gene sensitizes their melanocytes to UV induced DNA damage and thereby increased its susceptibility to UV induced skin cancer [35,53,55]. However no clear correlation with polymorphisms in MC1R and erythema induced by UVB have been proved [56-58]. The function of human MC1R variants are also extremely diverse, and it seems that different human MC1R variants may affect different melanocyte pathways.

However studies on mouse models described below show diverse effects of Mc1r on melanoma. While lack of the Mc1r in Mc1r $\mathrm{r}_{\mathrm{e} / \mathrm{e}}$ mice with the B-Raf V600E mutation increased development of melanoma [59], in a mouse model with HGF/SF overexpression mice homozygous for the Mclr (e/e) mutation with deficient $\mathrm{Mclr}$ signaling, do not develop melanoma [28]. The human MC1R polymorphisms that confer increased melanoma risk yield a receptor with the potential to retain some function which is lacking in recessive yellow mice, where the Mc1r receptor loses all signaling [28]. Moreover the effects on melanoma may not be specific to the particular (e) mutation. For instance Gray Lipizzaner horses carrying a loss-of-function mutation in ASIP (agouti signaling protein) that results in higher levels of Mclr had a higher incidence of melanoma, implying that increased Mclr signaling promotes melanoma in these animals [60]. Along these lines, in the Sinclair Swine pig model of melanoma, while black pigs are melanoma-prone, yellow pigs, that are thought to carry either MC1R or ASIP mutations, are resistant [61].

\section{Mclr and HGF}

HGF is the only known ligand of the c-Met receptor (receptor tyrosine kinase). Upon HGF binding, the c-Met receptor can activate various signaling pathways including AKT/PI3K/mTOR, RAS/MAPK and STAT pathways [62] which are highly relevant to melanoma. 
Aberrant c-Met activation correlates with hyperproliferation, metastasis, tumour angiogenesis and poor prognosis in various human cancers.

Pigmented, black transgenic HGF/SF neonatal mice are more susceptible than albino HGF/SF animals to melanoma, notably to UVA-induced melanoma, suggested to be as a result of oxidative interactions between UVA and eumelanin [12,27]. HGF does not affect melanin synthesis but increases the number of extra-follicular melanocytes resulting in a hyperpigmented phenotype [12,27]. Interestingly while overexpression of HGF increases the number of extra-follicular melanocytes in the trunk skin of FVB and C57-BL/6 mice, which further increase with mouse age, this does not occur in HGF transgenic e/e mice. C57BL/6-Mc1r ${ }^{\mathrm{e} / \mathrm{e}}$-HGF mice had few extrafollicular melanocytes, even though transgenic HGF and c-Met were expressed. Both C57BL/6-Mc1r ${ }^{\mathrm{e} / \mathrm{e}}$ and $\mathrm{C} 57 \mathrm{BL} / 6-\mathrm{Mc}_{\mathrm{r}} \mathrm{r}^{\mathrm{e}} \mathrm{e}-\mathrm{HGF}$ have yellow hair and black eyes, and similar amounts of pheomelanin [28]. Lack of melanomas in C57BL/6-Mc1re/e-HGF mice, either in response to UV radiation or spontaneously is consistent with this deficiency of extra-follicular melanocytes [28]. The importance of Mc1r in the extrafollicular survival of melanocytes complements the findings of Chou et al. 2013 who showed that in wild-type mice, Mc1r played an important role in migration of melanocytes from the hair follicle to the epidermis after wounding or UV radiation, a process that does not require transgenic HGF [63]. In our studies, heterozygous C57BL/6$\mathrm{Mclr}^{\mathrm{e} /+-\mathrm{HGF}}$ mice, which were indistinguishable from $\mathrm{Mclr}$ competent $\mathrm{C} 57 \mathrm{BL} / 6-\mathrm{Mc}^{+} \mathrm{r}^{+/+}-\mathrm{HGF}$ with similar numbers of dermal melanocytes and eumelanin levels in the skin, nevertheless produced significantly fewer melanomas. Impaired melanoma formation in these heterozygous animals indicates that a previously unrecognized pigment independent interaction between c-Met and Mclr interaction is necessary for melanoma in this model [28]. It can be speculated that a molecule that regulates signaling pathways of Mclr and c-Met, is PTEN (phosphatase and tensin homolog) may be responsible. Studies on melanoma and other cancers such as hepatocellular carcinoma and epithelioid sarcoma, show that PTEN can inhibit both PI3K/AKT/ mTOR and HGF/c-MET pathways [64,65]. PTEN loss plays an important role in melanoma [65]. Cao et al. show a UVB-dependent interaction between human MC1R and PTEN, a negative regulator of $\mathrm{AKT}$, that protects PTEN from degradation thus limiting AKT activation [67]. Polymorphisms in MC1R show to impair UV-induced binding to PTEN, resulting in senescence in cultured melanocytes [67]. Therefore it is possible that in heterozygous C57BL/6-Mclr-e ${ }^{\mathrm{e}+}$ HGF transgenic mice, due to lower expression of Mclr, PTEN can play important role in inhibition of UV-induced melanoma but this remains to be established.

\section{Mc1r and BRAF}

B-RAF, a member of the Raf kinase family of growh signal transduction protein kinases, is a key component of MAPK pathway (mitogen- activated protein kinases, also known as the Ras-Raf-MEKERK pathway), which regulates cell proliferation and differentiation. Despite the fact that B-RAF mutation occurs both in melanoma $(60-80 \%)$, and in pigmented lesions $[68,69]$, the role of UV damage in BRAF mutation remains unknown. Studies of Cao et al. showed a synergism between MC1R variants and B-RAFV600E in cellular transformation of genetically engineered human immortalized melanocytes [67], but an association between MC1R polymorphisms and B-RAF mutations in human melanoma is not well established, and it has been reported by some groups but not by others [70- 72]. Mitra et al. [59] found that in a mouse model carrying the B-Raf V600E mutation, spontaneous melanomas occurred in Mclr deficient (C57BL/6-B-Raf CA- Mc1r ${ }^{\mathrm{e} / \mathrm{e}}$ ) yellow mice due to the presence of phaeomelanin [59]. However there was no information on UV melanomas in this model. In contrast, no mutations in B-Raf were found in HGF-transgenic mouse tumors (unpublished observations, 73). Moreover, HGF/SF does not affect the quality of melanin, nor the efficiency of melanogenesis, but only the number and localization of melanocytes. In contrast to $\mathrm{C} 57 \mathrm{BL} / 6-\mathrm{HGF} / \mathrm{SF}$ transgenic mice, C57BL/6-B-Raf CA mice do not have extra-follicular melanocytes and arising melanomas are exclusively dermal without epidermal component. Recent studies have shown that the role of HGF in melanoma is not dependent on activated B-RAF signaling in human melanomas, and that HGF can mediate escape from B-RAF inhibition through activation of the MAPK and PI3K-AKT pathways [74,75]. Therefore the effect of the $\mathrm{Mclr}^{\mathrm{e} / \mathrm{e}}$ mutation on melanoma in mouse models not dependent on B-RafV600E or HGF should be established.

\section{Conclusion}

Since melanoma is one of the most malignant tumors and is resistant to many traditional therapies, the hope lay in recently introduced molecularly targeted therapies in which mutated genes and impaired pathways are blocked by specific inhibitors. Notably B- RAF inhibitors have been used with partial success and use of c-Met inhibitors has been proposed. However for understanding and better efficiency of therapeutic procedures more extended mechanistic studies on animal models are necessary.

\section{Acknowledgements}

I would like to thank Professor Frances Noonan and Professor Edward De Fabo for careful proofreading of the manuscript and critical discussion.

\section{References}

1. Rubinstein M, Stein S, Udenfriend S (1978) Characterization of proopiocortin, a precursor to opioid peptides and corticotropin. Proc Natl Acad Sci U S A 75: 669-671.

2. Liotta AS, Loudes C, McKelvy JF, Krieger DT (1980) Biosynthesis of precursor corticotropin/endorphin-, corticotropin-, alphamelanotropin-, beta-lipotropin-, and beta-endorphin-like material by cultured neonatal rat hypothalamic neurons. Proc Natl Acad Sci U S A 77: $1880-1884$

3. García-Borrón JC, Sánchez-Laorden BL, Jiménez-Cervantes C (2005) Melanocortin-1 receptor structure and functional regulation. Pigment Cell Res 18: 393-410.

4. Abdel-Malek Z, Scott MC, Suzuki I, Tada A, Im S, et al. (2000) The melanocortin-1 receptor is a key regulator of human cutaneous pigmentation. Pigment Cell Res 13 Suppl 8: 156-162.

5. Wakamatsu K, Ito S (2002) Advanced chemical methods in melanin determination. Pigment Cell Res 15: 174-183.

6. Lin JY, Fisher DE (2007) Melanocyte biology and skin pigmentation. Nature 445: 843-850.

7. Ito S; IFPCS (2003) The IFPCS presidential lecture: a chemist's view of melanogenesis. Pigment Cell Res 16: 230-236.

8. Rana BK, Hewett-Emmett D, Jin L, Chang BH, Sambuughin N, et al. (1999) High polymorphism at the human melanocortin 1 receptor locus. Genetics 151: 1547-1557.

9. Wikberg JE, Muceniece R, Mandrika I, Prusis P, Lindblom J, et al. (2000) New aspects on the melanocortins and their receptors. Pharmacol Res 42: 393-420. 
10. Rees JL (2000) The melanocortin 1 receptor (MC1R): more than just red hair. Pigment Cell Res 13: 135-140.

11. Wolnicka-Glubisz A, Pecio A, Podkowa D, Kolodziejczyk LM, Plonka PM (2012) Pheomelanin in the skin of Hymenochirus boettgeri (Amphibia: Anura: Pipidae). Exp Dermatol 21: 537-540.

12. Wolnicka-Glubisz A, Pecio A, Podkowa D, Plonka PM, Grabacka M (2013) HGF/SF increases number of skin melanocytes but does not alter quality or quantity of follicular melanogenesis. PLoS One 8: e74883.

13. Abdel-Malek ZA, Scott MC, Furumura M, Lamoreux ML, Ollmann M, et al. (2001) The melanocortin 1 receptor is the principal mediator of the effects of agouti signaling protein on mammalian melanocytes. J Cell Sci 114: 1019-1024.

14. Robbins LS, Nadeau JH, Johnson KR, Kelly MA, Roselli-Rehfuss L, et al (1993) Pigmentation phenotypes of variant extension locus alleles result from point mutations that alter MSH receptor function. Cell 72: 827-834.

15. Abdel-Malek ZA (2001) Melanocortin receptors: their functions and regulation by physiological agonists and antagonists. Cell Mol Life Sci 58: 434-441.

16. Jackson IJ, Budd PS, Keighren M, McKie L (2007) Humanized MC1R transgenic mice reveal human specific receptor function.Hum Mol Genet 16: 2341-2348.

17. Donatien PD, Hunt G, Pieron C, Lunec J, Taieb A, et al. (1992) The expression of functional MSH receptors on cultured human melanocytes. Arch Dermatol Res 284: 424-426.

18. Roberts DW, Newton RA, Beaumont KA, Helen Leonard J, Sturm RA (2006) Quantitative analysis of MC1R gene expression in human skin cell cultures. Pigment Cell Res 19: 76-89.

19. Slominski A, Plonka PM, Pisarchik A, Smart JL, Tolle V, et al. (2005) Preservation of eumelanin hair pigmentation in proopiomelanocortindeficient mice on a nonagouti (a/a) genetic background. Endocrinology 146: 1245-1253.

20. Krude H, Biebermann H, Luck W, Horn R, Brabant G, et al. (1998) Severe early-onset obesity, adrenal insufficiency and red hair pigmentation caused by POMC mutations in humans. Nat Genet 19: 155-157.

21. Krude H, Biebermann H, Schnabel D, Tansek MZ, Theunissen P, et al. (2003) Obesity due to proopiomelanocortin deficiency: three new cases and treatment trials with thyroid hormone and ACTH4-10. J Clin Endocrinol Metab 88: 4633-4640.

22. De Fabo EC (2005) Arctic stratospheric ozone depletion and increased UVB radiation: potential impacts to human health. Int J Circumpolar Health 64: 509-522.

23. Whiteman DC, Whiteman CA, Green AC (2001) Childhood sun exposure as a risk factor for melanoma: a systematic review of epidemiologic studies.Cancer Causes Control 12: 69-82.

24. Wolnicka-Glubisz A, Noonan FP (2006) Neonatal susceptibility to UV induced cutaneous malignant melanoma in a mouse model. Photochem Photobiol Sci 5: 254-260.

25. Noonan FP, Recio JA, Takayama H, Duray P, Anver MR, et al. (2001) Neonatal sunburn and melanoma in mice. Nature 413: 271-272.

26. De Fabo EC, Noonan FP, Fears T, Merlino G (2004) Ultraviolet B but not ultraviolet A radiation initiates melanoma. Cancer Res 64: 6372-6376.

27. Noonan FP, Zaidi MR, Wolnicka-Glubisz A, Anver MR, Bahn J, et al. (2012) Melanoma induction by ultraviolet A but not ultraviolet B radiation requires melanin pigment. Nat Commun 3: 884 .

28. Wolnicka-Glubisz A, Strickland FM, Wielgus A, Anver M, Merlino G, et al. (2014) A melanin-independent interaction between Mclr and Met signaling pathways is required for HGF-dependent melanoma. Int $\mathrm{J}$ Cancer

29. Takayama H, La Rochelle WJ, Anver M, Bockman DE, Merlino G (1996) Scatter factor/hepatocyte growth factor as a regulator of skeletal muscle and neural crest development. Proc Natl Acad Sci U S A 93: 5866-5871.

30. Takayama H, LaRochelle W J, Sharp R, Otsuka T, Kriebel P, et al. (1997). Diverse tumorigenesis associated with aberrant development in mice overexpressing hepatocyte growth factor/scatter factor. Proc.Natl. Acad. Sci. USA, 94: 701-706.

31. Wolnicka-Glubisz A, Damsker J, Constant S, Corn S, De Fabo E, et al. (2007) Deficient inflammatory response to UV radiation in neonatal mice. J Leukoc Biol 81: 1352-1361.

32. Richards DB, Lipton JM (1984) Effect of alpha-MSH 11-13 (lysineproline-valine) on fever in the rabbit. Peptides 5: 815-817.

33. Ceriani G, Diaz J, Murphree S, Catania A, Lipton JM (1994) The neuropeptide alpha-melanocyte-stimulating hormone inhibits experimental arthritis in rats. Neuroimmunomodulation 1: 28-32.

34. Böhm M, Wolff I, Scholzen TE, Robinson SJ, Healy E, et al. (2005) alphaMelanocyte-stimulating hormone protects from ultraviolet radiationinduced apoptosis and DNA damage. J Biol Chem 280: 5795-5802.

35. Scott MC, Suzuki I, Abdel-Malek ZA (2002) Regulation of the human melanocortin 1 receptor expression in epidermal melanocytes by paracrine and endocrine factors and by ultraviolet radiation. Pigment Cell Res 15: 433-439.

36. Abdel-Malek ZA, Knittel J, Kadekaro AL, Swope VB, Starner R (2008) The melanocortin 1 receptor and the UV response of human melanocytes--a shift in paradigm. Photochem Photobiol 84: 501-508.

37. Chakraborty AK, Funasaka Y, Slominski A, Ermak G, Hwang J et al. (1996) Production and release of proopiomelanocortin (POMC) derived peptides by human melanocytes and keratinocytes in culture: regulation by ultraviolet B. Biochim Biophys Acta 1313: 130- 138.

38. Skobowiat C, Dowdy JC, Sayre RM, Tuckey RC, Slominski A (2011) Cutaneous hypothalamic-pituitary-adrenal axis homolog: regulation by ultraviolet radiation. Am J Physiol Endocrinol Metab 301: E484-493.

39. Holzmann H, Altmeyer P, Stöhr L, Chilf GN (1983) [Modification of alpha-MSH by UVA irradiation of the skin]. Hautarzt 34: 294-297.

40. Cui R, Widlund HR, Feige E, Lin JY, Wilensky DL, et al. (2007) Central role of $\mathrm{p} 53$ in the suntan response and pathologic hyperpigmentation. Cell 128: 853-864.

41. Slominski A, Wortsman J (2003) Self-regulated endocrine systems in the skin. Minerva Endocrinol 28: 135-143.

42. Manna SK, Aggarwal BB (1998) Alpha-melanocyte-stimulating hormone inhibits the nuclear transcription factor NF-kappa B activation induced by various inflammatory agents. J Immunol 161: 2873- 2880.

43. Ichiyama T, Sakai T, Catania A, Barsh GS, Furukawa S, et al. (1999) Inhibition of peripheral NF-kappaB activation by central action of alphamelanocyte-stimulating hormone. J Neuroimmunol 99: 211-217.

44. Hiltz ME, Lipton JM (1989) Antiinflammatory activity of a COOHterminal fragment of the neuropeptide alpha-MSH.FASEB J 3 : 2282-2284.

45. Lipton JM, Catania A (1998) Mechanisms of antiinflammatory action of the neuroimmunomodulatory peptide alpha-MSH. Ann N Y Acad Sci 840: 373-380.

46. Grabbe S, Bhardwaj RS, Mahnke K, Simon MM, Schwarz T, et al. (1996) alpha-Melanocyte-stimulating hormone induces hapten-specific tolerance in mice. J Immunol 156: 473-478.

47. Getting SJ, Christian HC, Lam CW, Gavins FN, Flower RJ, et al. (2003) Redundancy of a functional melanocortin 1 receptor in the antiinflammatory actions of melanocortin peptides: studies in the recessive yellow (e/e) mouse suggest an important role for melanocortin 3 receptor. J Immunol 170: 3323-3330.

48. Wolnicka-Glubisz A, De Fabo E, Noonan F (2013) Functional melanocortin 1 receptor $\mathrm{Mclr}$ is not necessary for an inflammatory response to UV radiation in adult mouse skin. Exp Dermatol 22: 226-228.

49. Zmijewski MA, Slominski AT (2013) Is Mclr an important regulator of non-pigmentary responses to UV radiation?Exp Dermatol 22: 790-791.

50. Böhm M, Luger TA, Steingräber AK, Goerge T (2013) Is MC1 dispensable for regulation of cutaneous inflammatory and immune responses? Exp Dermatol 22: 792-794.

51. Healy E, Jordan SA, Budd PS, Suffolk R, Rees JL, et al. (2001) Functional variation of MC1R alleles from red-haired individuals. Hum Mol Genet 10: $2397-2402$ 
Citation: Wolnicka-Glubisz A (2014) Role of Mc1r in UV-Induced Melanoma in Animal Models. J Carcinog Mutagen 5: 200. doi: $10.4172 / 2157-2518.1000200$

Page 5 of 5

52. Schiöth HB, Phillips SR, Rudzish R, Birch-Machin MA, Wikberg JE, et al. (1999) Loss of function mutations of the human melanocortin 1 receptor are common and are associated with red hair.Biochem Biophys Res Commun 260: 488-491.

53. Fitzpatrick TB (1988) The validity and practicality of sun-reactive skin types I through VI. Arch Dermatol 124: 869-871.

54. Scott MC, Wakamatsu K, Ito S, Kadekaro AL, Kobayashi N, et al. (2002) Human melanocortin 1 receptor variants, receptor function and melanocyte response to UV radiation. J Cell Sci 115: 2349-2355.

55. Beaumont KA, Newton RA, Smit DJ, Leonard JH, Stow JL, et al. (2005) Altered cell surface expression of human MC1R variant receptor alleles associated with red hair and skin cancer risk. Hum Mol Genet 14: 2145-2154.

56. Palmer JS, Duffy DL, Box NF, Aitken JF, O'Gorman LE, et al. (2000) Melanocortin-1 receptor polymorphisms and risk of melanoma: is the association explained solely by pigmentation phenotype? Am J Hum Genet 66: 176-186.

57. Flanagan N, Ray AJ, Todd C, Birch-Machin MA, Rees JL (2001) The relation between melanocortin 1 receptor genotype and experimentally assessed ultraviolet radiation sensitivity. J Invest Dermatol 117: 1314-1317.

58. Ha TK, Waterston K, Bisset Y, Ray A, Rees JL (2003) Time course of ultraviolet $\mathrm{B}$-induced erythema in people with red hair harbouring homozygous melanocortin 1 receptor mutations. Exp Dermatol 12: 514-517.

59. Mitra D, Luo X, Morgan A, Wang J, Hoang MP, et al. (2012) An ultraviolet-radiation-independent pathway to melanoma carcinogenesis in the red hair/fair skin background. Nature 491: 449-453.

60. Rosengren Pielberg G, Golovko A, Sundström E, Curik I, Lennartsson J, et al. (2008) A cis-acting regulatory mutation causes premature hair graying and susceptibility to melanoma in the horse. Nat Genet 40: 1004-1009.

61. Lamoureux ML, Delmas V, Larue L, et al. The colors of mice: a model genetic network. Oxford UK: Wiley-Blackwell, 2010. 312 p.

62. Birchmeier C, Birchmeier W, Gherardi E, Vande Woude GF (2003) Met, metastasis, motility and more. Nat Rev Mol Cell Biol 4: 915-925.

63. Chou WC, Takeo M, Rabbani P, Hu H, Lee W, et al. (2013) Direct migration of follicular melanocyte stem cells to the epidermis after wounding or UVB irradiation is dependent on Mclr signaling. Nat Med 19: 924-929.

64. Venepalli NK, Goff L (2013) Targeting the HGF-cMET Axis in Hepatocellular Carcinoma. Int J Hepatol 2013: 341636

65. Imura Y, Yasui H, Outani H, Wakamatsu T, Hamada K, et al. (2014) Combined targeting of mTOR and c-MET signaling pathways for effective management of epithelioid sarcoma. Mol Cancer 13: 185.

66. Conde-Perez A, Larue L (2012) PTEN and melanomagenesis. Future Oncol 8: 1109-1120.

67. Cao J, Wan L, Hacker E, Dai X, Lenna S, et al. (2013) MC1R is a potent regulator of PTEN after UV exposure in melanocytes. Mol Cell 51: 409-422.

68. Brose MS, Volpe P, Feldman M, Kumar M, Rishi I, et al. (2002) BRAF and RAS mutations in human lung cancer and melanoma. Cancer Res 62: 6997-7000.

69. Davies H, Bignell GR, Cox C, Stephens P, Edkins S, et al. (2002) Mutations of the BRAF gene in human cancer. Nature 417: 949-954.

70. Scherer D, Rachakonda PS, Angelini S, Mehnert F, Sucker A, et al. (2010) Association between the germline MC1R variants and somatic BRAF/ NRAS mutations in melanoma tumors. J Invest Dermatol 130: 2844-2848.

71. Thomas NE, Kanetsky PA, Edmiston SN, Alexander A, Begg CB, et al. (2010) Relationship between germline MC1R variants and BRAF-mutant melanoma in a North Carolina population-based study. J Invest Dermatol 130: 1463-1465.

72. Landi MT, Bauer J, Pfeiffer RM, Elder DE, Hulley B, et al. (2006) MC1R germline variants confer risk for BRAF-mutant melanoma. Science 313: 521-522.

73. Gaffal E, Landsberg J, Bald T, Sporleder A, Kohlmeyer J, et al. (2011) Neonatal UVB exposure accelerates melanoma growth and enhances distant metastases in Hgf-Cdk4(R24C) C57BL/6 mice. Int J Cancer 129: 285-294.

74. Straussman R, Morikawa T, Shee K, Barzily-Rokni M, Qian ZR, et al. (2012) Tumour micro-environment elicits innate resistance to RAF inhibitors through HGF secretion. Nature 487: 500-504.

75. Wilson TR, Fridlyand J, Yan Y, Penuel E, Burton L, et al. (2012) Widespread potential for growth-factor-driven resistance to anticancer kinase inhibitors. Nature 487: 505-509. 